$\xi=$

\title{
Motivational Factors and Challenges in Managing Record for Mobile Work
}

\author{
Nur Atiqaf Mahathir, Irwan Kamaruddin Kadir, Masitah Ahmad, Noorzeelawati Norolazmi, Zakira Imana Harun, \\ Noorsyahirah Mohammad Mobin, Mohd Ridwan Seman @ Kamarulzaman. \\ Faculty of Information Management, University Teknologi MARA (UiTM Selangor) Puncak Perdana Campus, Shah Alam, Malaysia. \\ * Corresponding author: * Nur Atiqaf Mahathir (1), Faculty of Information Management, University Teknologi MARA *(UiTM Selan- \\ gor) Puncak Perdana Campus, Shah Alam, Malaysia. \\ E-mail: nuratiqaf.mahathir@gmail.com
}

\begin{abstract}
Mobile work is not a new phenomenon, but it is a result of better record-keeping records management. Apart from the development of electronic records and record-keeping systems, the practice of these functions continues to be office and paper-based and has supposedly been digitized. Mobile devices and online connections have enabled record creation beyond the office context, on other premises. The several of format in information management created challenges for preservation, until the point when a few researchers called it 'digital archaeology'. Mobile workers did their task in changing and unpredictable areas. Handling of records and document management was either straightforwardly in work situation or as soon as possible after the working hours. It may have implied working while at the same time going, at home or in different places, for example, while going to meeting or courses and customers' premises. Record management was important because it is often necessary to measures the importance areas in the organization. It is also to guarantee their continuity even if individual or that individual might leave the organization. In this issues, when we work as a team example for same related project and all of our colleagues will need the up to date documentation and also records related to their task. They also will share all the information regularly.
\end{abstract}

Keywords: Record Management, Mobile Workers, Mobile Work

\section{Introduction}

Records are "information that have been maintained and used as confirmation or authorized and information by an affiliation, organization or individual, in similarity of bona fide duties or in the exchange of business process".

Records management is the administration process in charge of the effective and efficient of the process to control of the creation of the record or document, receipt, maintenance, use and disposition of records itself. The techniques forms for catching and keeping up confirmation of information or data about business activities and trades considered as records management. The working environment in the office is carried out to obtain has been moving extremely in the last couple of decades.

Today, technology has become an enabler of mobile work. Most of the job task is done outside the workstation, which is in various different and unpredictable location, because of the difference in changes of mobile computing system and telecommunication based on Allen and Shoard Weilenmann [1]. For a mobile worker, the most important structures of the technology used are must easy access to document, make sure that can be access timely, user interface must be user friendly, ubiquity, and compliance with level of security policies [2]. It's more easily and flexible if have an options to work progressively ahead popularity among employers and employees in recent years. Organizations with mobile workers can save money on office space and technology equipment while growing their overall productivity.
Meanwhile, remote workers can enjoy the freedom to work from anywhere they want, they also can cut down on time and manage to spent their money on transportation, and have a better sense of the nature work-life balance. These elements are also functional in a differences way between records management in utilizing conservative data and communication technologies or portable mobile technologies are also to be concern. Nowadays, can be seen that are more individuals or organization can accept this working environment and have an ideas of working away from the office because of the advances in information technology and also record management practices. The flexibility of time management when we work remotely far from office will increase the different concern on health and safety for all of the staffs in the organization. This also about the key performance to make sure that all the staffs are ready to work anytime, anywhere when needed.

\section{Problems Statement}

A problem statement is a brief description of the issues that need to be addressed in the research process. Problem statement also has been used to get the overview and focus all of the team members at the beginning of investigation process. We also need to ensure that keep on track during the investigation, will help to validate the effort of delivered outcomes can be used to solve the problem statement. There are several problems been address in this study regarding to this mobile work environment: 


\section{Lack of motivation and awareness}

Organization does not have the motivation to invest in hiring mobile workers. They still believe in traditional ways of working environment that worker are still in office or at workstation and run all the work process from office. Worker also have to stay up at the office if they want to used the system / record management system in order to do their task. Organization do not have the initiative to provide cloud computing system that their worker can used and work away from office. Venezia, Allee and Schwabehas indicate that organizations should think through undertaking a review of their typical workspace and reassign space in greater arrangement with the needs and expectations of an increasingly mobile workers population. There are several ways can be considered to create a more cooperative and effective workplace [3] Bosch-Sijtsema, Virpi Ruohomäki \& Matti Vartiainen define that the vital elements either delay or enable knowledge work productivity in distributed team is like a team tasks, team structure and processes, the physical, virtual and social workspaces, as well as organizational context [4].

Based on Mäkinen and Henttonen people and document at their work activities, share information and keep their colleagues up-todate about what has take place in their work, in order to organize their own and team's work. They also have examined what are the motivations factors for an organization to invest in records management, especially in a mobile working environment. They propose that in some organizations there is a ordinary need to have a good records management and that individual to give motivations for records management are strictly linked to their own work and organizational culture [5].

\section{Challenges faced by Mobile Workers}

They have a lot of mobile technology that rapidly changing. They have to make sure their system can be compatible with the system that they currently use. Then, they also will face with issues of internet connection to access to their system because not all places have a good internet connection and this can cause delay on delivery their task. A mobile worker's is unclear by information retrieval using several devices, and managing interruptions, uncertainty, and changing of work locations. Error! Bookmark not defined. In addition, social functions and required technologies, multi-location work has challenged the knowledge sharing among organizational is a learning process. The changes in workplaces and use of alternative offices have had a great effect on the organizations itself.

\section{Problem/Issues in Mobile Work Environment}

In this new era, when we are required to work far from organization of our own office, such as attending seminar or outstation we do really need enough IT equipment, record management system, and basic office facilities. When staffs faced the problems in mobile work environment at their organization they also will take it that as opportunity to improve because normally this the small group of staffs will work remotely far from the office. Mobile devices dependent problems were related to the changing of the environments and circumstances in mobile work. Technical and usability problems were compounded and related to the poor network connections, poor capacity of mobile devices, and synchronization or compatibility of multiple devices. Technical matters usually could not be solved by innovative thinking like information management problems. Those of issues were not necessarily dependent on the worker but they usually could be worked out by technology support like the changing of the information technology. The problems of access to information are probably most familiar to mobile workers like how to unpack and plug in a laptop in an unfamiliar environment, how to access remotely records management system and databases, how to print a file how to transfer a file, and how to secure a confidential file. The problem was more substantial if the record was created collectively [6].

The document which is being amended is always in the same place. The record might also have a creator who is responsible for that distinct record. The increasing trend for mobile workers to bring their own devices to work, will creating a new set of productivity options while raising the spectre of information security. They are several issues related to the level of security as theft or stolen device, viruses and spyware, incident of data loss, employees connecting to unsecured networks personnel computer have been hacked, concerned or very concerned about mobile malware, and is also a worry or are concerned or very frightened by their IT managers.

\section{Research Objectives}

Research objectives may be linked with a hypothesis or used as a statement of purpose in a study that does not have a hypothesis. Research objectives are generally expressed in lay terms. It is also are focused as much to the user as to the researcher. The research objectives of this paper are attempts:

- to identify motivational factors in mobile work environment related to records management

- to identify challenge/issues of mobile workers in mobile work environment related to records management

- to study how do mobile workers solve these problems of record management in mobile work environment

\section{Research Questions}

A research question is the fundamental core of a research project, study, or evaluation of past literature and research. It also focuses the areas of study, decides about the methodology, and guides all stages of inquiry, analysis, and reporting process. This research questions will help to address the problems or issues raised during the research process:

- What are the motivational factors towards record management in mobile works environment?

- What kind of challenges perceived by mobile workers related to records management?

- How do mobile workers solve these problems/issues of record management in mobile work environment?

\section{Literature Review}

A literature review is the process regarding surveys from scholarly articles, books and any other sources that a relevant to particular issues, areas of research, or even theory, and it is also will provides a description, brief summary, and critical evaluation of these works in relation to the research problem being examine. Mobile work and information technology have been growing and become a main focused general. Jakob E Bardram and Clouse Bossen argue that attention will arise from two sources. Firstly, it has increased from understanding without IT support and work of collaborative will bring new and difficult problems. Secondly, it raises from remote mobility anywhere, mobile workers that are travel across large distance and focus on new technology improvements that also enable them to work more easily [7]. Mobile workers need to move regularly and access resources using certain computer applications. They face some of the challenges during working hours as some equipment, systems, databases and internet connectivity do not meet their needs as well as their working environment. This will also cause their work quality to be affected.

\section{Motivational Factors}

It can be hypothesized that the organization provides motivation to employees in record management to update, control or record a more comprehensive process than the organization without the same motivation. Internal motivations are more important for users than instead of thinking of records management as a single entity we should perhaps consider it as a palette of partly independent records management activities, like capturing and storing information, organising information, controlling access, and managing the lifecycle of the record management based on Sari Mäkine and Henttonen Pekka [4]. 
According to Allen and Shoard, the culture of the organization has been moving near to a more open information environment, with information being shared more generously and widely. Research in mobile work collaboration focuses only on technical issues such as connection support and remote access while working. They do not grab the opportunity to growth and improve workforce for long distance workers. We believe there are some drawbacks in research on non-technical issues that are essential to designing mobile collaboration systems, removing the relationship between the context of collaboration and mobility [1]. They also think that as long as workers who work far away are able to carry out their daily tasks without any of these problems will not cause major problems. The design of mobile system interaction is a complex activity as it only takes into new perspective of the usage of the record management and user experience aspects to exploit the peculiar features of mobile devices, such as its well-known and global nature.

The delivery aspects explains the co-ordinating effort which is not only required cooperative work but also focuses on the temporary aspect of co-operative work which is lead to the successful of the record management in a digital environment itself. However, if it is possible to make cooperation in managing records and working online, it will open the mind of the organization to prioritize the field of record management electronically as we are aware today is more towards digital [7].

Mobile workers are people who spend most of time for traveling and working at different places by using their mobile application such as laptop, PDAs, mobile phone etc. Technologies in their work, and whose work involves some level of knowledge intensity and while communication with others such as their colleagues, business partner and also clients [8]. Axtell and Cousins, defines that the ability as a possible act of relationship between perpetrator and technology [9]. Venezia and Allee note that mobile workers need work space, technology supplies, technical support and training, where to send letters and meet their friends, customers, and socialization customers who are more comfortable and conducive. An analysis of social networks or organizations can also be used to enhance the flow of knowledge and search for expertise by focusing on individual communication streams [10]. Mobile work is not a new phenomenon, but it is a result of better recordkeeping records management so this innovation will also be something that is difficult to achieve. Apart from the development of electronic records and records systems storage, this function continues to be office and paper-based and has been supposed to have been capitalized. Mobile devices and online connections have enabled record creation beyond the office context, on other premises.

According to the Vartianen said that unplanned mobile workspace is how the organization handles the management of mobile workers information. Mobile worker days are blurred by information retrieval using multiple devices, and managing uncertainties, disruptions and changing locations. Combining mobile tools and information-related activities, found that mobile professionals have specific requirements for technology that can accommodate information requirements flexibly under uncertain circumstances. It also shows that there are more technological implications of integrating the access and distribution of electronic documents with cellular technology [11]. Jakob E Bardram and Clouse Bossen.. This suggests, even though they face a small number of issues while performing the task but if they practice the wellmanaged record policy all these can be overcome [3]. Adriessen and Vartiainen stated without doubt, mobile technologies are the one of the main drivers of mobile work. Mobile tools are one of the challenges in this mobile work such as mobile devices, application and services are mentioned in many chapters of the book [11].

\section{Problems/issues in Mobile Works Environment}

$\mathrm{Ng}$ stated that the physical characteristics include amount of space, layout, ambient conditions and internet and Wi-Fi connectivity. To be effective, mobile workers perform different tasks at different workplaces that support those specific work tasks [12]. Nowadays, the easiness of usage of information technology (IT) solutions and their lower costs to adopt these forms of work, leading considerable benefits also for small and medium enterprises (SMEs), which by nature exhibit simple organizational structures and limited financial resources to invest in organizational innovations, Raguseo, Paolucci and Neirotti [13]. WhileVenezia and Allee stated that although the mobile work program is supported on a corporate level, but still doesn't successfully enough to reduce our office expenses because they do not have enough expertise in this working environment to guide them [10]. Issues that arise such as human interaction have attracted the attention of many researchers in a wide range of research fields concerned with technology including Computer Mediated Communication (CMC), for sociology of interaction, and workplace studies to measure the interest in mobile work [14]. Kakiharaa and Sørensen. The innovative technology has improved the opportunities to work from everywhere so as to reduce the travelling and make the experts more free to resolve upon how, where and when to carry out their work based on Wiberg and Ljungberg [15].

\section{Methodology}

The process used to collect data and information to make decisions. Methodologies can usually include research papers, interviews, surveys and other research techniques, and may include current and historical information. Research uses qualitative methods to collect data.

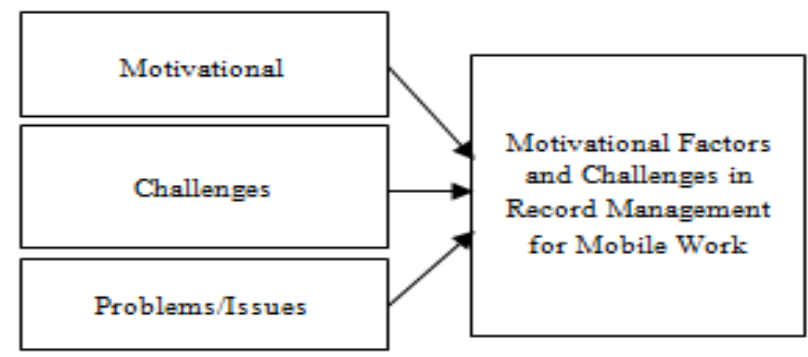

Figure 1: Conceptul framework for Motivational Factors and Challenge that Influence Record Management in Mobile Works

\section{Data Collection and Analysis}

This is also phases of data that have been collect, process and measuring that particular information on targeted variables which then enables to answer important questions and evaluate the outcomes for the research process. Data collection approach for this research is:

- Questionnaire

- Literature Review / Past Research

- Participant of Mobile Workers in SME company

- Participant of Mobile Workers in IT company

Data sampling or data collection will be collect from staff in a SME company which in auditing, accountancy, secretary and IT. This company involves with four fields but they used one server to store all their record and for the physical record they maintain stored in their two offices. A total of 20 staffs in this company will be the respondent. Four (4) of staff is working away from their office (mobile worker). Others staff also sometimes work far from office like outstation and etc. Data analysis, also known as data analytics or analysis of data, is a process of inspecting, cleansing, transforming, and modelling data with the goal of discovering useful information, it is also a process of suggesting conclusions, and supporting decision-making. 


\section{Conclusion}

This study plays its role in finding findings. Results from various causes and at various levels are also helpful in this research. The need for more systematic review of mobile work problems and its relationship to organizational record management is due to the lack of awareness to update digital records while working far from the organization. In the future, expertise must strive to better understand the exchange of records management practices, organizational work, objectives, and context [16]. The relationship between the management of personal workers' personal information and organizational records management policies and tools should be studied [17]. Records and information management policies and practices need to be improved so they can support flexible and mobile work better. In this way, organizational memories will be captured more efficiently [18]

\section{Reference}

[1] Allen, D. K., Shoard, M. Spreading the Load: Mobile Information and Communication Technologies and Their Effect on Information Overload. Information Research, 10 (2). Available at: [http://informationr.net/ir/10-2/paper227.html ] Last accessed 4 April 2013. 2004. Retrieve on 13 November 2016, http://dx.doi.org/10.1108/09565691111186867

[2] Lamming, M., Eldridge, M., Flynn, M., Jones, C. \&Pendlebury, D. Satchel: providing access to any document, anytime, anywhere. ACM Transactions on Computer-Human Interaction, 7(3), September, 322-352. 2000. Retreive on 19 December 2016 from http://citeseerx.ist.psu.edu/viewdoc/download?doi=10.1.1.2.3897\&r ep=rep $1 \&$ type $=$ pdf

[3] Venezia, C., Allee, V. \&Schwabe, O. Designing productive spaces for mobile workers: role insights from network analysis. Information Knowledge Systems Management. 2008. 7(1-2), 61-75.

[4] Bosch-Sijtsema, P.M., Ruohomäki, V. \&Vartiainen, M. Knowledge work productivity in distributed teams. Journal of Knowledge Management. 2009 13(6), 533-546.

[5] Mäkinen, Sari, \& Henttonen, Pekka. Motivations for records management in mobile work.Records Management Journal. 2011. 21(3), 188-204

[6] Perry, M., O'Hara, K., Sellen, A., Brown, B. \& Harper, R. Dealing with Mobility: Understanding Access Anytime, Anywhere. ACM Transactions on Computer-Human Interaction. 2001; 8 (4), 323 347.

[7] Bardram, J. E., Bossen, C. Mobility Work: The Spatial Dimension of Collaboration at a Hospital. Computer Supported Cooperative Work. 2005; 14, 131-160.

[8] Axtell, C., Hislop, D., \& Whittaker, S. Mobile technologies in mobile spaces: Findings from the context of train travel. International Journal of Human-Computer Studies. 2008; 66(12), 902-915.

[9] Cousins, K., \& Robey, D. Managing work-life boundaries with mobile technologies: An interpretive study of mobile work practices. Information Technology \& People, 28(1), 34-71. 2015. Retrieve on 13 November 2016 http://dx.doi.org/10.1108/ITP-08-2013-0155

[10] Venezia, C., \&Allee, V. Supporting mobile worker networks: components for effective workplaces. Journal of Corporate Real Estate, 9(3), 168-182. 2007. Retrieve on 27 October 2016 fromhttp://dx.doi.org/10.1108/14630010710845758

[11] Vartiainen, Matti. Mobile Virtual Work - Concepts, Outcomes and Challenges. In Mobile Virtual Work, pp. 13-44. Springer Berlin Heidelberg, 2006. Retrieve on 18 December 2016 from http://link.springer.com/chapter/10.1007/3-540-28365-X_2\#page-1

[12] $\mathrm{Ng}, \mathrm{C}$. F., \& $\mathrm{Ng}, \mathrm{C}$. F. Public spaces as workplace for mobile knowledge workers. Journal of Corporate Real Estate, 18(3), 209 223. 2016. Retrieved on 28 October 2016 from http://dx.doi.org/10.1108/JCRE-10-2015-0030

[13] Raguseo, E., Paolucci, E., \&Neirotti, P. Exploring the tensions behind the adoption of mobile work practices in SMEs. Business Process Management Journal, 21(5), 1162-1185. 2015. Retrieved on 12 November 2016 from http://dx.doi.org/10.1108/BPMJ-12-20130155

[14] Kakihara, M., \&Sørensen, C. Practising mobile professional work: tales of locational, operational, and interactional mobility. Info, 6(3), 180-187. 2004. Retrieved on 10 November 2016 from http://dx.doi.org/10.1108/14636690410549507
[15] Wiberg, M., \&Ljungberg, F. Exploring the vision of anytime, anywhere in the context of mobile work. In Knowledge Management and Virtual. 1999. Retrieve on 11 November 2016 from http://citeseerx.ist.psu.edu/viewdoc/summary?doi=10.1.1.26.9820

[16] Mäkinen, S. Mobile work and its challenges to personal and collective information management. Information Research, 17(3). 2012 Retrieve on 18 December 2016 from http:irinformationresearch.

[17] Weilenmann, A. Doing mobility: towards a new perspective on mobility. 2003. In Proceedings of the 26th information systems research seminar in Scandinavia, Haikko.

[18] Hallett, Tony. The five biggest security risks for mobile workers. Telegraph Media Group Limited. 2014. Retried on July 15, at: http://www.telegraph.co.uk/sponsored/technology/4g-mobile/datasecurity/10614504/security-risks-networks-apps.html. 